\title{
REVIEW
}

\section{Can aerobic exercise protect against dementia?}

Neill R Graff-Radford*

\begin{abstract}
There are more than 36 million people in the US over the age of 65 , and all of them are impacted by the cognitive decline and brain atrophy associated with normal aging and dementia-causing conditions like Alzheimer's disease, Lewy body disease, and vascular dementia. Recently, moderate exercise and improved fitness have been shown to enhance cognition in cognitively normal older persons as well as in individuals who complain of memory difficulty. Additionally, fitness correlates with brain volume in persons who are cognitively normal and those with Alzheimer's disease. Exercise in mouse models causes neurogenesis in the dentate gyrus. This review will discuss animal experiments, epidemiology, limited prospective studies, and biomarker data that make the case that prospective blinded studies are urgently needed to evaluate the role of aerobic exercise in protecting against dementia.
\end{abstract}

\section{Introduction}

In 2005, in the US, 36 million persons were over 65. Strong evidence indicates that memory and other cognitive tasks start declining at age 50 [1]. Furthermore, in the US, the prevalence of dementia ranges from $5 \%$ to $10 \%[2,3]$ and that of mild cognitive impairment (MCI) ranges from $12 \%$ to $18 \%[4,5]$. Cognitive decline is common in persons over 70 and has an important impact on quality of life. To improve the quality of life for older persons, it is imperative that we begin to understand which factors contribute to cognitive decline and brain atrophy. Furthermore, we need to determine which biomarkers or neurological measures can be used to predict these conditions and what therapeutic interventions can improve an individual's brain health. Recently, moderate exercise and improved fitness were shown to enhance cognition in cognitively normal older persons as well as in individuals who complain of memory difficulty [6].

*Correspondence: graffradford.neill@mayo.edu

Mayo Clinic Jacksonville, 4500 San Pablo Road, Jacksonville, FL 32224, USA
Additionally, fitness correlates with brain volume in persons who are cognitively normal [7] and in those with Alzheimer's disease (AD) [8]. In this paper, we shall discuss the following:

1. The causes of cognitive decline in older persons and why exercise could be a broad-spectrum intervention for dementia.

2. After this, we shall present epidemiological evidence that exercise may slow cognitive decline and decrease the chance of dementia.

3. Then we shall discuss the randomized control trials that provide evidence that exercise has a positive effect on improving cognition.

4. Following that, the paper will report the animal studies showing that exercise may be protective of the brain.

5. Lastly, we shall discuss biomarkers, starting with imaging and moving onto telomeres, plasma measures, cerebrospinal fluid (CSF) measures, and inflammatory biomarkers.

\section{A. Causes of cognitive decline in older persons}

The three most common forms of dementia are AD, Lewy body disease (LBD), and vascular dementia (VaD) [9] and all contribute to cognitive decline and brain atrophy. Noting that mixed dementia (having overlapping contributions) is common, Dickson and colleagues [9] reported that, in the Florida Brain Bank, the most frequent pathologies contributing to dementia were $\mathrm{AD}$ (77\%), followed by LBD (26\%), and then $\mathrm{VaD}(18 \%)$. In support of this finding is a paper by the Rush group [10], which reported the pathological and cognitive findings from two prospective community-based studies; in 652 patients who had come to autopsy, the three pathologies above were significantly associated with the cognitive measures.

Compelling studies show that cognitively normal older persons frequently have $\mathrm{AD}$ pathology. In 2,661 autopsy cases, Braak and Braak [11] reported that $27 \%$ of persons over 70 and 39\% over 75 have significant amyloid (stages $\mathrm{B}$ and $\mathrm{C}$ ) and tau (greater than stage III) pathology. In support of this observation, amyloid $A \beta$ imaging in cognitively normal older individuals revealed that $21 \%$ [12] to $30 \%$ [13] had positive scans. A recent study [14] indicates that the prevalence curve by age for positive Pittsburgh compound-B (PIB) scans in cognitively 
normal persons overlies the prevalence of amyloid plaque measures from Braak and Braak's [11] autopsy study in nondemented persons. Very interestingly, this curve parallels the $\mathrm{AD}$ prevalence curve but is 15 years earlier than the AD curve. This 15-year window may be the opportunity to prevent $\mathrm{AD}$ with interventions such as exercise. We also point out that, in the Rush communitybased study [10], AD pathology, vascular disease, and Lewy body pathology are common in cognitively normal persons.

\section{B. Could exercise be a broad-spectrum intervention?}

It has long been known that exercise may have many health benefits. Studies suggest that it decreases mortality [15], improves cardiovascular function [16], enhances cognitive functioning $[17,18]$, decreases coronary heart disease [19], decreases fall risk in older persons [20], and improves depression [21]. Barnes and colleagues [22], in a review, summarized the effects of exercise on obesity, vascular disease, hypertension, diabetes, and inflammation and how all of these factors may be protective of the brain. It is possible that exercise helps protect against the three most common dementia pathologies. In an $\mathrm{AD}$ transgenic mouse model, Lazarov and colleagues [23] showed that environmental enrichment, including an exercise wheel, decreased $A \beta$ brain deposits. In the rodent Parkinson disease (PD) models, exercise was protective against motor but not cognitive tasks [24] and improved the density of blood vessels and mRNA vascular endothelial growth factor (VEGF) activity in the nigra [25]. Clinically, Crizzle and colleagues [26] reviewed exercise and PD and concluded that 'patients with PD improve their physical performance and activities of daily living through exercise'. But that review did not address cognitive improvement. Lastly, there is good evidence that exercise may be protective against stroke and $\mathrm{VaD}[27,28]$.

\section{Epidemiological studies on exercise show protective effects on cognition}

2A. Exercise may preserve cognition and slow cognitive decline

Yaffe and colleagues [29] followed 5,925 women (more than 65 years old) for 6 to 8 years with baseline selfreport exercise measures. Women with a greater physical activity level at baseline experienced less cognitive decline during the 6 to 8 years of follow-up: cognitive decline occurred in $17 \%, 18 \%, 22 \%$, and $24 \%$ of those in the highest, third, second, and lowest quartiles of blocks walked per week, respectively $(P<0.001$ for trend).

Weuve and colleagues [30] used baseline energy expenditure measures from a survey of 18,766 nurses. The authors found, on a global cognitive score, that women in the second through fifth quintiles of energy expenditure scored an average of, respectively, 0.06, 0.06, 0.09, and 0.10 standard units higher than women in the lowest quintile ( $P$ for trend $<0.001)$. The authors also observed less cognitive decline among women who were more active, especially those in the two highest quintiles of energy expenditure.

A recent report by Middleton and colleagues [31] noted that women who gave a history of being physically active at any time in life, especially as teenagers, had a lower chance of cognitive decline in late life. Nine thousand three hundred forty-four women (65 years old or older, mean 71.6 years) self-reported teenage, age 30 , age 50, and late-life physical activity. Women who reported being physically active had a lower prevalence of cognitive impairment in late life than women who were inactive at each stage.

\section{B. Exercise is associated with decreased incident dementia}

Abbott and colleagues [32], in a study of 2,257 men, reported that men who walked the least $(<0.25$ miles/day) experienced a 1.8-fold excess risk of dementia in comparison with those who walked more than 2 miles/day (17.8 versus $10.3 / 1,000$ person-years; relative hazard 1.77 , 95\% confidence interval [CI] 1.04 to 3.01 ).

Larson and colleagues [7] followed 1,740 persons (older than 65 years) for an average of 6.2 years with respect to incident dementia. The incidence rate was 13.0 per 1,000 person-years for participants who exercised three or more times per week in comparison with 19.7 per 1,000 person-years for those who exercised less. The age- and sex-adjusted hazard ratio of dementia was 0.62 (95\% CI 0.44 to $0.86 ; P=0.004$ ).

In a population-based study [33] of physical exercise frequency between 198 subjects with MCI and 1,126 cognitively normal subjects, moderate exercise was less common in the MCI group. The odds ratios for any frequency of moderate exercise were 0.61 (95\% CI 0.43 to $0.88 ; P=0.008$ ) for midlife (age of 50 to 65 years) and 0.68 (95\% CI 0.49 to $0.93 ; P=0.02$ ) for late life.

A recent meta-analysis reported by Hamer and Chida [34] included 16 studies with exercise measures, including 163,797 controls at baseline and 3,219 incident cases of dementia or PD. The authors found that the relative risks in the highest physical activity category compared with the lowest were 0.72 (95\% CI 0.60 to $0.86 ; P<0.001)$ for dementia, 0.55 (95\% CI 0.36 to $0.84 ; P=0.006$ ) for $\mathrm{AD}$, and 0.82 (95\% CI 0.57 to $1.18 ; P=0.28$ ) for PD. While this provides support that exercise may be protective against dementia, there is less support of its being protective against dementia in PD.

Aarsland and colleagues [28] completed a meta-analysis evaluating whether exercise might protect against $\mathrm{VaD}$ and found five studies that met criteria for 
meta-analysis, including 10,108 nondemented control subjects and 374 individuals with $\mathrm{VaD}$. The meta-analysis demonstrated a significant association between physical exercise and a reduced risk of developing $\mathrm{VaD}$ (odds ratio $0.62,95 \%$ CI 0.42 to 0.92 ).

\section{Randomized control trials}

A recent Cochrane systematic review of 11 studies of aerobic exercise programs for healthy older persons [35] indicated that 8 of the studies reported cognitive improvement associated with fitness improvement. According to the review, the largest and most consistent cognitive effects in meta-analyses were observed on measures of cognitive speed and attention. Changes across other cognitive domains (for example, memory, language, and visuospatial) were also present but varied across individual studies.

In a single-blind study [6] from Australia, moderate exercise (50 minutes three times per week for 6 months) was shown to enhance cognition in cognitively normal older persons as well as in individuals who complained of memory difficulty. This was a randomized controlled trial of a 24-week physical activity intervention with a total of 170 participants, and 138 participants completed the 18 -month assessment. The main outcome measure was the Alzheimer's Disease Assessment Scale-Cognitive Subscale (ADAS-Cog) at 18 months. The investigators found that, in an intent-to-treat analysis, participants in the intervention group improved 0.26 points $(95 \%$ CI -0.89 to 0.54$)$ and those in the usual care group deteriorated 1.04 points (95\% CI 0.32 to 1.82 ) on the ADAS-Cog at the end of the intervention. This showed a modest improvement at 18 months after 6 months of exercise intervention.

In a randomized control trial by Erikson and colleagues [36], 120 cognitively normal sedentary adults from 55 to 80 years old were randomly assigned to aerobic exercise (building up to walking 40 minutes four times per week) or toning and stretching. The authors found that the hippocampi in the aerobics group increased by $1 \%$ to $2 \%$ per year whereas in the stretching group the hippocampi decreased by $1.4 \%$ per year. The authors measured fitness with peak oxygen consumption, and the better the fitness, the larger the hippocampi on the magnetic resonance imaging (MRI) measures. Greater elevations in serum brain-derived neurotrophic factor (BDNF) correlated with greater hippocampal volume gain. Those with better fitness at baseline and at 12 months scored better on memory tests. This study shows the usefulness of biomarkers in understanding the effects of aerobic exercise.

A pilot MCI exercise study [37] of 16 males and 17 females randomly assigned to aerobic exercise or stretching for 6 months reported that aerobic exercise improved executive function in both men and women. Exercise also increased glucose disposal and reduced fasting plasma insulin, cortisol, and BDNF in women and increased plasma insulin-like growth factor I in men.

\section{Animal studies \\ 4A. What other factors that may improve brain health does exercise impact?}

A review by Cotman and colleagues [38] indicates that exercise affects growth factors such as BDNF, increases synaptic plasticity, increases neurogenesis, and reduces peripheral factors such as diabetes, hypertension, and cardiovascular disease. The authors suggest a common mechanism of exercise on both the peripheral and central effects in that decreasing inflammation increases successful brain function.

\section{B. Mouse models of Alzheimer's disease and exercise}

van Praag and colleagues [39] showed that voluntary exercise alone increased dentate gyrus neurogenesis. This is separate from environmental enrichment, which also increases neurogenesis.

Ambree and colleagues [40] showed the interaction between an active lifestyle and AD pathology in female TgCRND8 mice carrying human APPswe+ind gene. These mice were housed in enriched housing in their cages. Four months in this environment resulted in a significant reduction of beta-amyloid plaques and amyloid angiopathy [40]. Costa and colleagues [41], in a similar study, showed that the environmental enrichment in transgenic mice improved the cognitive functioning and decreased the brain $A \beta$ pathology. Adlard and colleagues [42] used the TgCRND8 transgenic mouse model and showed that 5 months of voluntary exercise resulted in a decrease in extracellular $A \beta$ plaques in the frontal cortex $(38 \% ; P=0.018)$, the cortex at the level of the hippocampus ( $53 \% ; P=0.0003$ ), and the hippocampus (40\%; $P=0.06)$. Long-term exercise also enhanced the rate of learning of TgCRND8 animals in the Morris water maze, with significant $(P<0.02)$ reductions in escape latencies over the first 3 (of 6) trial days.

Lazarov and colleagues [23] reported that exposure of transgenic mice to an 'enriched environment', including an exercise wheel, resulted in reductions in cerebral $A \beta$ levels and amyloid deposits in comparison with animals raised under 'standard housing' conditions. The authors found that the enzymatic activity of an $A \beta$-degrading endopeptidase, neprilysin, is elevated in the brains of 'enriched' mice and inversely correlated with $A \beta$ burden. Lastly, in a recent paper, $\mathrm{Hu}$ and colleagues [43] reported that, in mice with the familial AD-linked mutant APPswe/ PS1DeltaE9, environmental enrichment enhanced neurogenesis and was accompanied by a significant reduction in levels of hyperphosphorylated tau and oligomeric $A \beta$. The authors concluded that 'environmental modulation 
can rescue the impaired phenotype of the Alzheimer's brain and that induction of brain plasticity may represent therapeutic and preventive avenues in $\mathrm{AD}^{\prime}$ [43].

\section{Biomarkers}

\section{A. Structural brain changes}

Cognitive decline is associated with brain atrophy in cognitively normal persons

Jack and colleagues [44] showed that in cognitively normal persons the change of brain atrophy over time is associated with a change in cognitive scores. The authors looked at change in hippocampal, whole brain, and ventricle volumes in relationship to the Mini-Mental Status Examination [45], Dementia Rating Scale [46], Rey Auditory Verbal Learning Test [47] and the logical memory subtest of the Weschler Memory Scale [48] and, using the Spearman rank correlation, found a significant correlation between change in all volume measures and change in all test scores.

\section{Associations between cardiovascular fitness and brain volume}

Exercise improves certain cognitive tasks but are these related to structural brain measures? One of the first studies showing that exercise influences the structure of the brain was by Colcombe and colleagues [49], who reported on 59 older persons, half of whom underwent aerobic training and half of whom participated in toning and stretching. The authors also measured maximal oxygen uptake. They found on MRI that gray and white matter brain areas increased in the aerobic but not the control group and this was related to a function of fitness training.

Burns and colleagues [8] showed that increased cardiorespiratory fitness $\left(\mathrm{VO}_{2}{ }^{\text {peak }}\right)$ is associated with increased brain volume, suggesting that increased fitness may be associated with decreased brain atrophy in AD.

In a study involving both mice and humans, Pereira and colleagues [50] showed that, as exercise improves fitness, there may be neurogenesis in the dentate gyrus, which in turn could improve learning. In mice, exercise-induced increases in dentate gyrus cerebral blood volume (CBV) were found to correlate with postmortem measurements of neurogenesis. In humans, exercise was found to have a primary effect on dentate gyrus CBV and this selectively correlated with cardiopulmonary (fitness) and cognitive (learning) function. From this, the authors extrapolated that exercise may induce neurogenesis in the dentate gyrus, which in turn may improve learning.

Erickson and colleagues [51] completed a crosssectional study evaluating hippocampal volume, aerobic fitness, and spatial memory in 165 nondemented older adults and found that (a) higher fitness levels were associated with larger hippocampi after age, sex, and years of education were controlled for; (b) larger hippocampi and higher fitness levels correlated with better spatial memory; and (c) hippocampal volume partially mediated the relationship between higher fitness levels and enhanced spatial memory, suggesting that exercise may be protective of hippocampus, which in turn preserves cognition. The authors point out that they used meditational analysis and that a causal effect should be interpreted cautiously because unmeasured factors such as diet could co-vary with hippocampal volume and account for the mediation. They suggest that future studies use longitudinal designs, clinical populations, and other measuring techniques to validate the finding.

\section{B. Telomeres}

Telomere length is a marker of cellular aging and has been associated with dementia [52]. A report [53] involving 2,401 twins found that leukocyte telomere length was 200 nucleotides longer in those most active compared with those least active. Twins discordant for exercise amount showed that twins doing more exercise had longer telomeres. Another study [54] showed that leukocyte telomere length was longer in duration trained individuals, with $\mathrm{VO}_{2}{ }^{\text {peak }}$ explaining $60 \%$ of the variance. The Health ABC study [55] reported that telomere length may serve as a biomarker of cognitive aging. The investigators noted that baseline telomere length was associated with digit symbol scores $(36.4,34.9$, and 34.4 points for long, medium, and short, respectively; $P<0.01$ ). The 7-year Modified Mini-Mental Status Examination change scores were lower among those with longer telomere length $(-1.7$ versus -2.5 and -2.9 points; $P=0.01)$. The investigators concluded that telomere length may serve as a biomarker for cognitive aging. There is a clear need for a prospective controlled study evaluating the effect of exercise on telomere length.

\section{C. Plasma $A \beta$}

Exercise is known to decrease inflammatory markers [56] and improve insulin sensitivity $[57,58]$. This is important because Cotman and colleagues [38] have postulated that the common mechanism whereby exercise improves brain health is through decreasing inflammation. We hypothesize that both $A \beta 40$ and $A \beta 42$ will decrease with exercise. Interestingly, a nonsignificant trend toward a decline in plasma A $\beta 42$ was observed in a small, MCI exercise study [37].

\section{D. Cerebrospinal fluid $A \beta 42$ and Pittsburgh compound-B scanning}

Liang and colleagues [59] reported a study of 69 older adults who had PIB and CSF measures of A $\beta 42$ and tau. The authors administered an exercise questionnaire estimating the amount of exercise performed in the 
previous 10 years. They found that those with increased PIB and tau had significantly lower exercise scores. The PIB association remained significant after adjustment for covariates. Those doing 7.5 metabolic equivalent task (MET) hours/week (which is equal to 30 minutes five times per week) had significantly lower PIB $(P=0.006)$ and higher CSF A $\beta 42(P=0.001)$ after covariates were controlled for.

A recent study [14] indicates that the prevalence curve by age for positive PIB scans in cognitively normal persons overlies the prevalence of amyloid plaque measures from Braak and Braak's [11] autopsy study in nondemented persons. Very interestingly, this curve parallels the AD prevalence by age but is 15 years earlier at each age. This 15 -year window may be the opportunity to prevent $\mathrm{AD}$ with interventions such as exercise.

\section{E. Inflammatory biomarkers}

Whereas cross-sectional studies show that inflammatory biomarkers such as C-reactive protein are lower in persons who exercise $[60,61]$, a randomized control trial did not show that exercise decreases $\mathrm{C}$-reactive protein [62].

\section{Conclusions}

There is increasing evidence from basic research, including transgenic mouse experiments, epidemiology, biomarkers, and a limited number of prospective studies, that aerobic exercise may be protective of brain health by changing chemical factors in the brain and warding off diseases and other factors related to brain disease, such as diabetes, hypertension, and inflammation. The time is ripe to do prospective studies to validate this assertion.

\section{Abbreviations}

AD, Alzheimer's disease; ADAS-Cog, Alzheimer's Disease Assessment ScaleCognitive Subscale; BDNF, brain-derived neurotrophic factor; CBV, cerebral blood volume; $\mathrm{Cl}$, confidence interval; CSF, cerebrospinal fluid; LBD, Lewy body disease; $\mathrm{MCl}$, mild cognitive impairment; $\mathrm{MRI}$, magnetic resonance imaging; PD, Parkinson disease; PIB, Pittsburgh compound-B; VaD, vascular dementia.

\section{Competing interests}

The author declares that he has no competing interests.

Published: 28 February 2011

References

1. Salthouse TA: Memory aging from 18 to 80 . Alzheimer Dis Assoc Disord 2003, 17:162-167

2. Plassman BL, Langa KM, Fisher GG, Heeringa SG, Weir DR, Ofstedal MB, Burke JR, Hurd MD, Potter GG, Rodgers WL, Steffens DC, Willis RJ, Wallace RB: Prevalence of dementia in the United States: the aging, demographics, and memory study. Neuroepidemiology 2007, 29:125-132.

3. Hebert LE, Scherr PA, Bienias JL, Bennett DA, Evans DA: Alzheimer disease in the US population: prevalence estimates using the 2000 census. Arch Neurol 2003, 60:1119-1122.

4. Petersen R, Roberts R, Knopman D, Geda YE, Pankratz V, Boeve B, Rocca WA: The Mayo Clinical Study of Aging: Incidence of Mild Cognitive Impairment. Alzheimers Dement 2008, 4:T130.

5. Roberts RO, Geda YE, Knopman DS, Cha RH, Pankratz VS, Boeve BF, Ivnik RJ,
Tangalos EG, Petersen RC, Rocca WA: The Mayo Clinic Study of Aging: design and sampling, participation, baseline measures and sample characteristics. Neuroepidemiology 2008, 30:58-69.

6. Lautenschlager NT, Cox KL, Flicker L, Foster JK, van Bockxmeer FM, Xiao J, Greenop KR, Almeida OP: Effect of physical activity on cognitive function in older adults at risk for Alzheimer disease: a randomized trial. JAMA 2008, 300:1027-1037.

7. Larson EB, Wang L, Bowen JD, McCormick WC, Teri L, Crane P, Kukull W: Exercise is associated with reduced risk for incident dementia among persons 65 years of age and older. Ann Intern Med 2006, 144:73-81.

8. Burns JM, Cronk BB, Anderson HS, Donnelly JE, Thomas GP, Harsha A, Brooks WM, Swerdlow RH: Cardiorespiratory fitness and brain atrophy in early Alzheimer disease. Neurology 2008, 71:210-216.

9. Barker WW, Luis CA, Kashuba A, Luis M, Harwood DG, Loewenstein D, Waters C, Jimison P, Shepherd E, Sevush S, Graff-Radford N, Newland D, Todd M, Miller B, Gold M, Heilman K, Doty L, Goodman I, Robinson B, Pearl G, Dickson $D$, Duara R: Relative frequencies of Alzheimer disease, Lewy body, vascular and frontotemporal dementia, and hippocampal sclerosis in the State of Florida Brain Bank. Alzheimer Dis Assoc Disord 2002, 16:203-212.

10. Dowling NM, Tomaszewski Farias S, Reed BR, Sonnen JA, Strauss ME, Schneider JA, Bennett DA, Mungas D: Neuropathological associates of multiple cognitive functions in two community-based cohorts of older adults. J Int Neuropsychol Soc 2010, 1-13.

11. Braak H, Braak E: Frequency of stages of Alzheimer-related lesions in different age categories. Neurobiol Aging 1997, 18:351-357.

12. Aizenstein HJ, Nebes RD, Saxton JA, Price JC, Mathis CA, Tsopelas ND, Ziolko SK, James JA, Snitz BE, Houck PR, Bi W, Cohen AD, Lopresti BJ, DeKosky ST, Halligan EM, Klunk WE: Frequent amyloid deposition without significant cognitive impairment among the elderly. Arch Neurol 2008, 65:1509-1517.

13. Jack CR Jr., Lowe VJ, Senjem ML, Weigand SD, Kemp BJ, Shiung MM, Knopman DS, Boeve BF, Klunk WE, Mathis CA, Petersen RC: 11C PiB and structural MRI provide complementary information in imaging of Alzheimer's disease and amnestic mild cognitive impairment. Brain 2008, 131:665-680.

14. Rowe CC, Ellis KA, Rimajova M, Bourgeat P, Pike KE, Jones G, Fripp J, TochonDanguy H, Morandeau L, O'Keefe G, Price R, Raniga P, Robins P, Acosta O, Lenzo N, Szoeke C, Salvado O, Head R, Martins R, Masters CL, Ames D, Villemagne $V L$ : Amyloid imaging results from the Australian Imaging, Biomarkers and Lifestyle (AIBL) study of aging. Neurobiol Aging 2010, 31:1275-1283.

15. Blair SN, Kohl HW 3rd, Paffenbarger RS Jr., Clark DG, Cooper KH, Gibbons LW: Physical fitness and all-cause mortality. A prospective study of healthy men and women. JAMA 1989, 262:2395-2401.

16. Blumenthal JA, Emery CF, Madden DJ, Coleman RE, Riddle MW, Schniebolk S, Cobb FR, Sullivan MJ, Higginbotham MB: Effects of exercise training on cardiorespiratory function in men and women older than 60 years of age. Am J Cardiol 1991, 67:633-639.

17. Colcombe SJ, Kramer AF, Erickson KI, Scalf P, McAuley E, Cohen NJ, Webb A, Jerome GJ, Marquez DX, Elavsky S: Cardiovascular fitness, cortical plasticity, and aging. Proc Natl Acad Sci U S A 2004, 101:3316-3321.

18. Lytle ME, Vander Bilt J, Pandav RS, Dodge HH, Ganguli M: Exercise level and cognitive decline: the MoVIES project. Alzheimer Dis Assoc Disord 2004, 18:57-64.

19. Leon AS: Physical activity levels and coronary heart disease. Analysis of epidemiologic and supporting studies. Med Clin North Am 1985, 69:3-20.

20. Lord SR, Castell S, Corcoran J, Dayhew J, Matters B, Shan A, Williams P: The effect of group exercise on physical functioning and falls in frail older people living in retirement villages: a randomized, controlled trial. J Am Geriatr Soc 2003, 51:1685-1692.

21. Freeman MA, Bell AS, Sommerville C: A hyperparasitic microsporidian infecting the salmon louse, Lepeophtheirus salmonis: an rDNA-based molecular phylogenetic study. J Fish Dis 2003, 26:667-676.

22. Barnes DE, Whitmer RA, Yaffe K: Physical activity and dementia: the need for prevention trials. Exerc Sport Sci Rev 2007, 35:24-29.

23. Lazarov O, Robinson J, Tang YP, Hairston IS, Korade-Mirnics Z, Lee VM, Hersh LB, Sapolsky RM, Mirnics K, Sisodia SS: Environmental enrichment reduces Abeta levels and amyloid deposition in transgenic mice. Cell 2005, 120:701-713.

24. Pothakos K, Kurz MJ, Lau YS: Restorative effect of endurance exercise on behavioral deficits in the chronic mouse model of Parkinson's disease with severe neurodegeneration. BMC Neurosci 2009, 10:6.

25. Villar-Cheda B, Sousa-Ribeiro D, Rodriguez-Pallares J, Rodriguez-Perez Al, 
Guerra MJ, Labandeira-Garcia JL: Aging and sedentarism decrease vascularization and VEGF levels in the rat substantia nigra. Implications for Parkinson's disease. J Cereb Blood Flow Metab 2009, 29:230-234.

26. Crizzle AM, Newhouse IJ: Is physical exercise beneficial for persons with Parkinson's disease? Clin J Sport Med 2006, 16:422-425.

27. Yung LM, Laher I, Yao $X$, Chen $Z Y$, Huang Y, Leung FP: Exercise, vascular wall and cardiovascular diseases: an update (part 2). Sports Med 2009, 39:45-63.

28. Aarsland D, Sardahaee FS, Anderssen S, Ballard C: Is physical activity a potential preventive factor for vascular dementia? A systematic review. Aging Ment Health 2010, 14:386-395

29. Yaffe K, Barnes D, Nevitt M, Lui LY, Covinsky K: A prospective study of physical activity and cognitive decline in elderly women: women who walk. Arch Intern Med 2001, 161:1703-1708

30. Weuve J, Kang JH, Manson JE, Breteler MM, Ware JH, Grodstein F: Physical activity, including walking, and cognitive function in older women. JAMA 2004, 292:1454-1461.

31. Middleton $L E$, Barnes DE, Lui LY, Yaffe $K$ : Physical activity over the life course and its association with cognitive performance and impairment in old age. J Am Geriatr Soc 2010, 58:1322-1326

32. Abbott RD, White LR, Ross GW, Masaki KH, Curb JD, Petrovitch H: Walking and dementia in physically capable elderly men. JAMA 2004, 292:1447-1453.

33. Geda YE, Roberts RO, Knopman DS, Christianson TJ, Pankratz VS, Ivnik RJ, Boeve BF, Tangalos EG, Petersen RC, Rocca WA: Physical exercise, aging, and mild cognitive impairment: a population-based study. Arch Neurol 2010, 67:80-86

34. Hamer M, Chida Y: Physical activity and risk of neurodegenerative disease: a systematic review of prospective evidence. Psychol Med 2009, 39:3-11.

35. Angevaren M, Aufdemkampe G, Verhaar HJ, Aleman A, Vanhees L: Physical activity and enhanced fitness to improve cognitive function in older people without known cognitive impairment. Cochrane Database Syst Rev 2008, CD005381.

36. Erickson KI, Voss MW, Prakash RS, Basak C, Szabo A, Chaddock L, Kim JS, Heo S, Alves $H$, White SM, Wojcicki TR, Mailey E, Vieira VJ, Martin SA, Pence BD, Woods $J A$, McAuley E, Kramer AF: Exercise training increases size of hippocampus and improves memory. Proc Natl Acad SciU S A 2011 Jan 31. [Epub ahead of print].

37. Baker L, Frank L, Foster-Schubert K, Green P, Wilkinson C, McTiernan A, Plymate S, Fishel M, Stennis Watson G, Cholerton B, Duncan G, Mehta P, Craft $\mathrm{S}$ : Cognitive effects of a controlled trial of aerobic exercise for MCl. Arch Neurol 2010, 67:71-79.

38. Cotman CW, Berchtold NC, Christie LA: Exercise builds brain health: key roles of growth factor cascades and inflammation. Trends Neurosci 2007 30:464-472.

39. van Praag H, Kempermann G, Gage FH: Running increases cell proliferation and neurogenesis in the adult mouse dentate gyrus. Nat Neurosci 1999, 2:266-270.

40. Ambree O, Leimer U, Herring A, Gortz N, Sachser N, Heneka MT, Paulus W, Keyvani K: Reduction of amyloid angiopathy and Abeta plaque burden after enriched housing in TgCRND8 mice: involvement of multiple pathways. Am J Pathol 2006, 169:544-552.

41. Costa DA, Cracchiolo JR, Bachstetter AD, Hughes TF, Bales KR, Paul SM, Mervis $\mathrm{RF}$, Arendash GW, Potter H: Enrichment improves cognition in AD mice by amyloid-related and unrelated mechanisms. Neurobiol Aging 2007. 28:831-844.

42. Adlard PA, Perreau VM, Pop V, Cotman CW: Voluntary exercise decreases amyloid load in a transgenic model of Alzheimer's disease. J Neurosci 2005, 25:4217-4221

43. Hu YS, Xu P, Pigino G, Brady ST, Larson J, Lazarov O: Complex environment experience rescues impaired neurogenesis, enhances synaptic plasticity, and attenuates neuropathology in familial Alzheimer's disease-linked APPswe/PS1DeltaE9 mice. FASEB J 2010, 24:1667-1681.
44. Jack CR Jr., Shiung MM, Gunter JL, O'Brien PC, Weigand SD, Knopman DS, Boeve BF, Ivnik RJ, Smith GE, Cha RH, Tangalos EG, Petersen RC: Comparison of different MRI brain atrophy rate measures with clinical disease progression in AD. Neurology 2004, 62:591-600.

45. Folstein MF, Folstein SE, McHugh PR: 'Mini-mental state'. A practical method for grading the cognitive state of patients for the clinician. J Psychiatr Res 1975, 12:189-198.

46. Mattis S: Dementia Rating Scale. Odessa: Psychological Assessment Resources; 1983.

47. Rey A: Léxamen en clinique psychologique. Paris: Presses Universitaires de France; 1964

48. Wechsler D: Wechsler Memory Scale-Revised. New York: The Psychological Corporation; 1987.

49. Colcombe SJ, Erickson KI, Scalf PE, Kim JS, Prakash R, McAuley E, Elavsky S, Marquez DX, Hu L, Kramer AF: Aerobic exercise training increases brain volume in aging humans. J Gerontol A Biol Sci Med Sci 2006, 61:1166-1170.

50. Pereira AC, Huddleston DE, Brickman AM, Sosunov AA, Hen R, McKhann GM, Sloan R, Gage FH, Brown TR, Small SA: An in vivo correlate of exerciseinduced neurogenesis in the adult dentate gyrus. Proc Natl Acad Sci U S A 2007, 104:5638-5643.

51. Erickson Kl, Prakash RS, Voss MW, Chaddock L, Hu L, Morris KS, White SM, Wojcicki TR, McAuley E, Kramer AF: Aerobic fitness is associated with hippocampal volume in elderly humans. Hippocampus 2009, 19:1030-1039.

52. Honig LS, Schupf N, Lee JH, Tang MX, MayeuX R: Shorter telomeres are associated with mortality in those with APOE epsilon4 and dementia. Ann Neurol 2006, 60:181-187.

53. Cherkas LF, Hunkin JL, Kato BS, Richards JB, Gardner JP, Surdulescu GL, Kimura M, Lu X, Spector TD, Aviv A: The association between physical activity in leisure time and leukocyte telomere length. Arch Intern Med 2008, 168:154-158.

54. Larocca TJ, Seals DR, Pierce GL: Leukocyte telomere length is preserved with aging in endurance exercise-trained adults and related to maximal aerobic capacity. Mech Ageing Dev 2010, 131:165-167.

55. Yaffe K, Lindquist K, Kluse M, Cawthon R, Harris T, Hsueh WC, Simonsick EM, Kuller L, Li R, Ayonayon HN, Rubin SM, Cummings SR: Telomere length and cognitive function in community-dwelling elders: findings from the Health ABC Study. Neurobiol Aging 2009 Dec 21. [Epub ahead of print].

56. Wilund KR: Is the anti-inflammatory effect of regular exercise responsible for reduced cardiovascular disease? Clin Sci (Lond) 2007, 112:543-555.

57. Craft S: The role of metabolic disorders in Alzheimer disease and vascular dementia: two roads converged. Arch Neurol 2009, 66:300-305.

58. Gill JM, Malkova D: Physical activity, fitness and cardiovascular disease risk in adults: interactions with insulin resistance and obesity. Clin Sci (Lond) 2006, 110:409-425

59. Liang KY, Mintun MA, Fagan AM, Goate AM, Bugg JM, Holtzman DM, Morris JC, Head D: Exercise and Alzheimer's disease biomarkers in cognitively normal older adults. Ann Neurol 2010, 68:311-318.

60. Hamer $\mathrm{M}:$ The relative influences of fitness and fatness on inflammatory factors. Prev Med 2007, 44:3-11.

61. Kasapis C, Thompson PD: The effects of physical activity on serum C-reactive protein and inflammatory markers: a systematic review. J Am Coll Cardiol 2005, 45:1563-1569.

62. Church TS, Earnest CP, Thompson AM, Priest EL, Rodarte RQ, Saunders T, Ross R, Blair SN: Exercise without weight loss does not reduce C-reactive protein: the INFLAME study. Med Sci Sports Exerc 2010, 42:708-716.

doi:10.1186/alzrt65

Cite this article as: Graff-Radford NR: Can aerobic exercise protect against dementia? Alzheimer's Research \& Therapy 2011, 3:6 